\title{
A tale of two ligands: angiopoietins, the endothelium, and outcomes
}

\author{
Jonathan M Siner \\ See related research by Fiusa et al., http://ccforum.com/content/17/4/R169
}

\begin{abstract}
Angiopoietins signal via the Tie-2 receptor and are essential molecules for vasculogenesis during development and in the adult state play roles in vascular stability as well as inflammation and appear to be involved in the dysregulation of the endothelium in illness. Angiopoietin-1 (Ang-1) and angiopoietin-2 (Ang-2) are, respectively, agonists and competitive partial agonists, which have been found to undergo alterations in individuals with sepsis. In sepsis, Ang-2 levels are elevated and Ang-1 is decreased. In the previous issue of Critical Care, Fiusa and colleagues measure circulating Ang-1 and Ang-2 along with other growth factors in humans with febrile neutropenia. The authors found that an increased Ang-2/Ang-1 ratio, or an elevated Ang-2 level, at the time of an initial fever, is associated with subsequent development of septic shock and death. These findings validate that the Ang-2/Ang-1 balance, which is thought to reflect overall signaling via the Tie-2 receptor, is relevant to outcomes in patients with sepsis. Importantly, the specimens were obtained far in advance of the development of septic shock, suggesting that detectable alterations in this pathway may provide early clues regarding outcomes. This study adds to the evidence that angiopoietins are early markers of endothelial dysfunction in sepsis and provide prognostic information regarding outcomes.
\end{abstract}

Correspondence: jonathan.siner@yale.edu

Pulmonary, Critical Care and Sleep Medicine, Yale School of Medicine, 300 Cedar Street, TAC-441 South, P.O. Box 208057, New Haven CT 06520-8057, USA
In the previous issue of Critical Care, Fiusa and colleagues [1] present the results of their inquiry into the prognostic value of a panel of growth factors in the development of septic shock and death in patients with febrile neutropenia. Endothelial growth factors play a critical role in vascular development and remodeling, and recent research has implicated angiopoietins, the newest member of this family, in the pathogenesis of sepsis [2-5]. Vascular endothelial growth factor (VEGF) is a promoter of vasculogenesis via its own receptors. Angiopoeitin-1 (Ang-1) promotes stabilization and maturation of new blood vessels, whereas angiopoietin-2 (Ang-2), which binds the same receptor (Tie-2), can either promote VEGF-induced angiogenesis or destabilize blood vessels, causing endothelial apoptosis and leakiness in a context-dependent fashion [2-4]. Animal studies demonstrate that administration of either Ang-1 or a synthetic Tie-2 agonist reduces vascular permeability and organ dysfunction [5-8]. Ang-2 increases vascular permeability, but it is also clear that activation or inhibition of the Tie-2 signaling pathway effects vascular stability and the production of inflammatory cytokines $[9,10]$. Investigations in critically ill humans suggest an association between circulating levels of Ang-1 and Ang2 and septic shock, acute lung injury, and mortality [11-14].

Fiusa and colleagues [1] investigated a population of patients with hematologic malignancies at high risk of development of septic shock due to immunosuppression. Importantly, as a result of the unique criteria used to identify the study candidates, the subjects were identified early in the course of their illness. The authors hypothesized that abnormalities in a panel of biomarkers would be associated with the development of septic shock in a population of patients with cancer and febrile neutropenia (Temperature $>38^{\circ} \mathrm{C}$ ) [1]. The authors enrolled 99 consecutive febrile neutropenia patients who had either acute leukemia or another hematologic malignancy (many had received stem cell transplantation). Specimens were 
obtained with the next scheduled blood draw after the fever, and exclusion criteria were minimized. In total, 20 of the 99 patients ultimately developed septic shock during the 28-day observation period, and the median time from enrollment to development of septic shock was 3 days. Ultimately, just over one-third of the patients were bacteremic from samples obtained during the febrile episode. The investigators measured Ang-2 and Ang-1 as well as VEGF-A, C-reactive protein (CRP), and soluble fms-like tyrosine kinase-1 (sFLT-1) and followed the patients prospectively for the development of septic shock and death. As single biomarkers, neither VEGF nor sFLT1 or Ang-1 (or CRP) was associated with development of septic shock. However, Ang-2 was significantly associated with the development of septic shock as was the ratio of Ang-2/Ang-1, which validated previous findings [15]. The authors also determined the sensitivity and specificity of each individual marker and determined the area under the curve (AUC) for each proposed biomarker. The AUC for the Ang-2/Ang-1 ratio was slightly larger (0.68) than that for either Ang-2 (0.66) or Ang-1 (0.63) alone, and all the other measured markers (CRP, VEGF-A, and sFLT-1) were not significant. In a multivariable analysis accounting for variations in platelets, neutrophils, CRP, and age, the risk of development of shock in those with elevated Ang-2/ Ang- 1 levels remained elevated. In addition, those with an Ang-2/Ang-1 ratio greater than either the median or 5.0 had significantly increased mortality.

This investigation further demonstrates that the information provided by measuring circulating levels of Ang-1 and Ang-2 contains prognostic information regarding outcomes in sepsis $[5,10,11,14,16,17]$. The novel feature of this investigation is the timing of the sample collection. Therefore, it is of great interest to observe that those with elevated Ang-2 and Ang-2/Ang-1 ratio already had alterations 72 hours prior to the development of septic shock as most prior studies have obtained their human specimens on those with more advanced sepsis [5,11-14]. The fact that derangements can be observed potentially farther in advance of the development of organ dysfunction or shock is of profound significance for those interested in therapy for sepsis $[1,16]$. Much as lactate has been used to identify septic patients who are at risk of progression in the setting of clinical stability, so too it appears that measurement of Ang-1 and Ang-2 is also capable of identifying individuals at risk for poor outcomes with enough advanced notice to allow time for intervention $[17,18]$. Although questions remain regarding the exact role of the angiopoietins in sepsis and whether they are central enough to the primary mechanisms of organ dysfunction to serve as therapeutic targets, it has become increasingly clear that the angiopoietins are more than simply regulators of vascular leakiness but are intimately involved in the dysregulation of the endothelium in sepsis by both vascular and inflammatory mechanisms and that assessment of these growth factors aids in prognosis $[10,17]$.

\section{Abbreviations}

Ang-1: Angiopoietin-1; Ang-2: Angiopoietin-2; AUC: Area under the curve; CRP: C-reactive protein; SFLT-1: Ssoluble fms-like tyrosine kinase-1; VEGF: Vascular endothelial growth factor.

\section{Competing interests}

The author declares that he has no competing interests.

Published: 16 Oct 2013

\section{References}

1. Fiusa MML, Costa-Lima C, de Souza GR, Vigorito AC, Aranha FJP, LorandMetze I, Annichino-Bizzacchi JM, de Souza CA, De Paula EV: A high angiopoietin-2/angiopoietin-1 ratio is associated with a high risk of septic shock in patients with febrile neutropenia. Crit Care 2013, 17:R169.

2. Maisonpierre PC, Suri C, Jones PF, Bartunkova S, Wiegand SJ, Radziejewski C, Compton D, Mclain J, Aldrich TH, Papadopoulos N, Daly TJ, Davis S, Sato TN, Yancopoulos GD: Angiopoietin-2, a natural antagonist for Tie-2 that disrupts in vivo angiogenesis. Science 1997, 277:55-60.

3. Lobov IB, Brooks PC, Lang RA: Angiopoietin-2 displays VEGF-dependent modulation of capillary structure and endothelial cell survival in vivo. Proc Natl Acad Sci U S A 2002, 99:11205-11210.

4. Thurston G, Suri C, Smith K, McClain J, Sato TN, Yancopoulous GD, McDonald DM: Leakage-resistant blood vessels in mice transgenically overexpressing angiopoietin-1. Science 1999, 286:2511-2514.

5. van der Flier M, van Leeuwen HJ, van Kessel KP, Kimpen JL, Hoepelman Al, Geelen SP: Plasma vascular endothelial growth factor in severe sepsis. Shock 2005, 23:35-38.

6. Kumpers P, Gueler F, David S, Slyke PV, Dumont DJ, Park JK, Bockmeyer CL, Parikh SM, Pavenstadt H, Haller H, Shushakova N: The synthetic Tie2 peptide vasculotide protects against vascular leakage and reduces mortality in murine abdominal sepsis. Crit Care 2011, 15:R261.

7. David S, Park JK, Meurs M, Zijlstra JG, Koenecke C, Schrimpf C, Shushakova N, Gueler F, Haller H, Kumpers P: Acute administration of recombinant Angiopoietin-1 ameliorates multiple-organ dysfunction syndrome and improves survival in murine sepsis. Cytokine 2011, 55:251-259.

8. Kim DH, Jung YJ, Lee AS, Lee S, Kang KP, Lee TH, Lee SY, Jang KY, Moon WS, Choi KS, Yoon KH, Sung MJ, Park SK, Kim W: COMP-angiopoietin-1 decreases lipopolysaccharide-induced acute kidney injury. Kidney Int 2009, 76:1180-1191.

9. Ziegler T, Horstkotte J, Schwab C, Pfetsch V, Weinmann K, Dietzel S, Rohwedder I, Hinkel R, Gross L, Lee S, Hu J, Soehnlein O, Franz WM, Sperandio M, Pohl U, Thomas M, Weber C, Augustin HG, Fassler R, Deutsch $U$, Kupatt C: Angiopoietin 2 mediates microvascular and hemodynamic alterations in sepsis. J Clin Invest 2013. Epub ahead of print.

10. Mankhambo LA, Banda DL, Jeffers G, White SA, Balmer P, Nkhoma S, Phiri H, Molyneux EM, Hart CA, Molyneux ME, Heyderman RS, Carrol ED: The role of angiogenic factors predicting clinical outcome in severe bacterial infection in Malawian children. Crit Care 2010, 14:R91.

11. Guiliano JS, Lahni PM, Harmon K, Wong HR, Dought LA, Carcillo JA, Zingarelli B, Sukhatme VP, Parikh SM, Wheeler DS: Admission angiopoietin levels in children with septic shock. Shock 2007, 28:650-654.

12. Parikh SM, Mammoto T, Schultz A, Yuan HT, Christiani D, Karamanchi SA, Sukhatme VP: Excess circulating angiopoietins-2 may contribute to pulmonary vascular leak in sepsis in humans. PLoS Med 2006, 3:e46.

13. Orfanos SE, Kotanidou A, Glynos C, Athansiou C, Tsigkos S, Dimopoulou I, Sotiropoulou C, Zakynthinos S, Armaganidis A, Papapetropoulos A, Roussos C: Angiopoietin-2 is increased in severe sepsis: correlation with inflammatory mediators. Crit Care Med 2007, 35:199-2006.

14. Siner JM, Bhandari V, Engle KM, Elias JA, Siegel MD: Elevated serum angiopoietin-2 levels are associated with increased mortality in sepsis. Shock 2009, 31:348-353.

15. Alves BE, Montalvao SA, Aranha FJ, Siegl TF, Souza CA, Lorand-Metze I, Annichino-Bizzacchi JM, De Paula EV: Imbalances in serum angiopoietins concentrations are early predictors of septic shock development in patients with post chemotherapy febrile neutropenia. BMC Infect Dis 2010, 10:143. 
16. Ricciuto DR, Dos Santos CC, Hawkes M, Toltl L, Conroy AL, Rajwans N, Lafferty El, Cook DJ, Fox-Robichaud A, Kahnamoui K, Kain KC, Liaw PC, Liles WC: Angiopoietin-2 and angiopoietin-1 as clinically informative prognostic biomarkers of morbidity and mortality in severe sepsis. Crit Care Med 2011, 39:702-710.

17. David S, Mukherjee A, Ghosh CC, Yano M, Khankin EV, Wenger JB, Karumanchi SA, Shapiro NI, Parikh SM: Angiopoietin-2 may contribute to multiple organ dysfunction and death in sepsis. Crit Care Med 2012, 40:3034-3041.

18. Early Goal Directed Therapy Collaborative Group, Rivers E, Nguyen B, Havstad S, Ressler J, Muzzin A, Knoblich B, Peterson E, Tomlanovich M: Early goal-directed therapy in the treatment of severe sepsis and septic shock. N Engl J Med 2001, 345:1368-1377.

\section{$10.1186 /$ cc13066}

Cite this article as: Siner: A tale of two ligands: angiopoietins, the endothelium, and outcomes. Critical Care 2013, 17:1007 